ScIDice

\section{A Data Analysis On Periapical Lesion Cases Undergoing Non Surgical Management - A Single Centered Retrospective Study}

Research Article

Immadi Laxmi Sujith Kumar ${ }^{1}$, Sindhu Ramesh ${ }^{2 *}$, Deepak S

${ }^{1}$ Department of Conservative Dentistry and Endodontics, Saveetha Dental College and Hospitals, Saveetha Institute of Medical and Technical Sciences, Saveetha University, Chennai, India.

${ }^{2}$ Professor, Department of Conservative Dentistry and Endodontics, Saveetha Dental College and Hospitals, Saveetha Institute of Medical and Technical Sciences, Saveetha University, Chennai, India.

${ }^{3}$ Senior Lecturer, Department of Conservative Dentistry and Endodontics, Saveetha Dental College and Hospitals, Saveetha Institute of Medical and Technical Sciences, Saveetha University, Chennai, India.

\title{
Abstract
}

\begin{abstract}
Aim: The purpose of this study was to evaluate the management of large periapical lesions non surgically in endodontic practice. Materials and Methodology: This retrospective single centered study aims at large periapical lesions that can be managed non surgically in Endodontic Practice. This study was based on an evaluation of the data of a total 48 clinical cases consisting of 48 teeth with signs and symptoms or radiographic evidence of periapical lesion were selected for this study.

Results: A total of 48 teeth have been treated endodontically for periapical lesion, in which 28 teeth are treated non surgically and 20 teeth are treated surgically. In this study we contemplate that there is no significant association between surgical and non surgical management $(\mathrm{p}>0.05)$.

Conclusion: Within the limitations of the study, nonsurgical management of the teeth can be done. This will simplify the treatment and conserve the tooth and adjacent structures. A total of 48 teeth exhibiting signs and symptoms or radiographic evidence of periapical disease were treated endodontically, irrespective of the age and sex of the patients. $58.3 \%$ of the teeth were treated non surgically and $41.7 \%$ of the teeth were treated surgically.
\end{abstract}

Keywords: Periapical Lesion; Non Surgical Management; Endodontic Management; Periradicular Lesion.

\section{Introduction}

Periapical lesions develop as corollary to pulpal disease. Often they occur without any incident of acute pain and are discovered on routine radiographic evaluation [1-9]. Therefore they maintain an enormous size before they are diagnosed. In the event that every single tooth were to be dealt with precisely, the blood and nerve flexibly of noncontiguous teeth may be harmed. So endodontic treatment of those teeth likewise would be imminent [10-14]. Most of the periapical lesions $(>90 \%)$ can be divided as dental granulomas, radicular cysts and abscesses [15-17]. The frequency of cysts within periapical lesions ranges between $6 \%$ and $55 \%$ [18]. The incidence of periapical granulomas rangs between $9.3 \%$ and $87.1 \%$ and of abscess between $28.7 \%$ and $70 \%$ [19, 20]. There's clinical proof that because the periapical lesions increase in size, the section of the radicular cysts increases. However, some sizable lesions are shown to be granulomas $[21,22]$. The actual diagnosis of a cyst can be made only by a histological examination. However, a preliminary clinical diagnosis of a periapical cyst can be made based on the following a) the periapical lesion is involved one or more non-vital teeth, b) the lesion is more than $200 \mathrm{~mm}^{2}$ in size, c) the lesion is seen radiographically as circumscribed, well defined radiolucent area bounded by a thin radiopaque line and, d) it produces a straw coloured fluid upon aspiration or as drainage through an pervade root canal system [23-27].

In children, surgical intervention may involve an excellent deal of stress and agony or require the utilization of general anesthesia for minor surgical treatments, like apicoectomy [28]. Surgical treatment would also cause greater bone loss [29, 30]. Therefore,

\section{*Corresponding Author:}

Sindhu Ramesh,

Professor, Department of Conservative Dentistry and Endodontics, Saveetha Dental College and Hospitals, Saveetha Institute of Medical and Technical Sciences, Saveetha University, Chennai, India.

Tel: 9840136543

E-mail: sindhuramesh@saveetha.com

Received: November 05, 2020

Accepted: November 18, 2020

Published: November 24, 2020

Citation: Immadi Laxmi Sujith Kumar, Sindhu Ramesh, Deepak S. A Data Analysis On Periapical Lesion Cases Undergoing Non Surgical Management - A Single Centered Retrospective Study. Int J Dentistry Oral Sci. 2020;S10:02:005:24-30. doi: http://dx.doi.org/10.19070/2377-8075-SI02-010005

Copyright: Sindhu Ramesh 2020 . This is an open-access article distributed under the terms of the Creative Commons Attribution License, which permits unrestricted use, distribution and reproduction in any medium, provided the original author and source are credited. 
such lesions might be treated non surgically, it might simplify the treatment for the patient, with minimal harm to the adjacent teeth and vital structures, and help preserve the bone [31-34].

The concept of nonsurgical treatment of periapical lesions is not new. In 1956 Sommer, Ostronder and Crowley reported a method of treatment and advocated that the I-shaped rubber dam wick be inserted in the periapical lesion and to be changed every two weeks [35]. This relieved the pressure in the cystic cavity and encouraged healing from the periphery. In about six to eight weeks time, the lesion regressed sufficiently to allow nonsurgical management of the involved teeth. In 1972, however, Bhaskar described a method of conservative treatment of radicular cysts, which involved a great deal of controversy, and since then there has been a renewed and sustained interest in this mode of treatment [36-40].

The eventual objective of endodontic treatment, should be to return the involved teeth to a state of health and function without surgical intervention [10]. All inflammatory periapical lesions should be initially treated with conservative non surgical procedures $[10,41]$. Surgical intervention is recommended only after non surgical techniques have failed $[42,43]$. Plus, surgical management has numerous disadvantages, which limit its utilization in the administration of periapical lesions $[44,45]$. Various studies have reported a success rate of upto $85 \%$ after endodontic treatment of teeth periapical lesions [46-48]. A high percentage of $94.47 \%$ of complete and partial healing of periapical lesions following nonsurgical endodontic therapy has also been reported [49]. The aim of the present study was planned to analyze the management of large periapical lesions without surgical intervention.

\section{Material and Methods}

\section{Study Design}

Single centered retrospective study.
Ethical Approval: Approval for the project was obtained from the Institutional Review Board of Saveetha Institute of Medical and Technical Sciences, Chennai, India on Date 18/04/2020. SDC/SIHEC/2020/DIASDATA/0619-0320.

\section{Eligibility Criteria}

Inclusion criteria: Teeth presenting with large periapical lesions, anterior and posterior teeth, patients with good systematic health, age group of $18-50$ years.

Exclusion criteria: Patients suffering from debilitating diseases, since their healing potential may have impaire, periodontally compromised teeth, teeth with calcified canals, teeth with external and internal resorption and patients over 50 yrs of age.

Data Extraction: This study was based on an evaluation of the data that met the inclusion and exclusion criteria. Data collection was accomplished using standardized electronic form designed to collect information related to subjects demographic features,teeth involved, management of the lesion, type of medicament placed, and number of visits for the treatment. The final data was exported to excel and saved on a secure server for analysis. The case selection and data extraction is shown in (Flow chart 1). Clinical presentations of cases are shown in (Table 1), the clinical findings included are acute infection with diffuse facial swelling, intraoral sinuses, gumboli or chronic proliferating granulation tissue mass with bone expansion and symptomatic teeth with periapical rarefaction.

Sample Size: A total of 48 clinical cases consisting of 48 teeth with signs and symptoms or radiographic evidence of periapical lesion were selected for this study, irrespective of age and sex. Data was collected after reviewing records of the patients between June 2019 and March 2020. Considering single centred retrospective study, multiple operators were involved in treatments to reduce selection bias. The parameters assessed in this study are

Flow Chart 1. Selection of Cases in the Study.

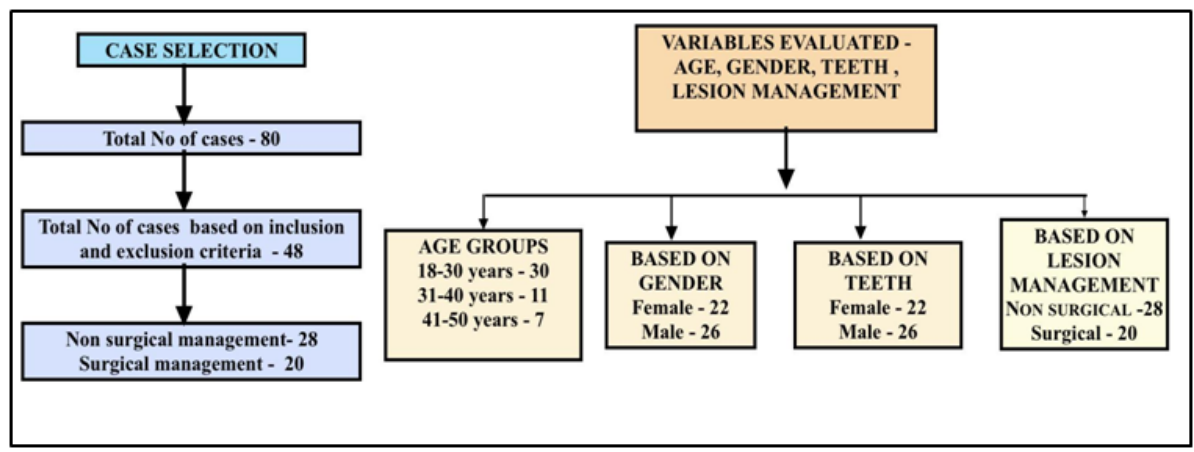

Table 1. Clinical Presentation of Cases.

\begin{tabular}{|c|c|}
\hline No. of cases (48) & Clinical findings \\
\hline 10 & Acute infection with diffuse facial swelling \\
\hline 8 & $\begin{array}{c}\text { Intraoral sinuses } \\
\text { tion tissue mass with bone expansion }\end{array}$ \\
\hline 12 & $\begin{array}{c}\text { Symptomatic free teeth with periapical } \\
\text { rarefaction }\end{array}$ \\
\hline 18
\end{tabular}


age, gender, anterior teeth and posterior teeth.

\section{Groups}

Periapical lesion management

Group A : Non surgical management of the lesion

Group B : Surgical management of the lesion

\section{Clinical Outcome}

The primary clinical outcome of non surgical management of the lesion is to conserve the tooth and adjustment structures, simplify the treatment for the patient and help in conserving the bone.

\section{Clinical Protocol}

Clinical protocol followed for the non surgical management are, vitality tests of the teeth are done and based on that access opening of the involved teeth is followed. Copious amounts of irrigants are used to flush out the root canal content and open dressing was given. For the next visits medicaments like calcium hydroxide and triple antibiotic paste are used for management of the lesion. Once the patients are asymptomatic then teeth are obturated.

\section{Statistical Analysis}

The data was imported from Excel for analysis and grouping of parameters was done. The parameters data was then copied into SPSS software and statistical analysis was done. Chi square test was used for statistical analysis. All analyses were performed using statistical software (SPSS inc., version 20, chicago, IL, USA) and $p$ value less than 0.05 was considered statistically significant.

\section{Results and Discussion}

A total of 48 teeth have been treated endodontically for periapical lesion, in which 28 teeth are treated non surgically and 20 teeth are treated surgically. Data on management of lesions non surgically is shown in (Graph 1), in which 26 anterior teeth and 2 posterior teeth are treated. Lesion sizes greater than $3 \times 3 \mathrm{~mm}$ are 3 and lesion sizes lesser than $3 \times 3 \mathrm{~mm}$ are 25 . Teeth treated in one visit are 6 and teeth treated in two visits are 22. Coming to the medicament used, in 7 teeth triple antibiotic paste in combination with calcium hydroxide has been placed and in 21 teeth only calcium hydroxide is placed. Data on surgical management of the lesion is shown in (Graph 4), in which 17 anterior teeth and 3 posterior teeth are treated. Lesion sizes greater than $3 \times 3 \mathrm{~mm}$ are 18 and lesion sizes lesser than $3 \times 3 \mathrm{~mm}$ are 2 . Teeth treated in two visits are 2 and teeth treated in three visits are 18. Triple antibiotic paste and calcium hydroxide combination has been used in all the teeth. Frequency tables are used to describe the variables in the study. Frequency of patients undergoing periapical lesion management across various age groups is shown in (Table 2) in which $62.5 \%$ are under age group 18-30 years, $22.9 \%$ are under age group $31-40$ years and $14.6 \%$ are under age group $41-50$ years. Frequency of periapical lesion management amongst gender is shown in (Table 3 ), most of them are males $(54.2 \%)$. Frequency of teeth underwent periapical lesion management is shown in (Table 4), among these anterior teeth are higher $(89.6 \%)$. Frequency of surgical and nonsurgical management of teeth is shown in (Table 5). The statistical analysis between surgical and non surgical management is shown in (graph 1). In this study we contemplate that there is no significant association between surgical and non surgical management $(p>0.05)$. The association between the and lesion management is shown in (Graph 2). The association between age

Table 2. Frequency of patients underwent periapical lesion management across various age groups. Out of which 18-30 years age group $(62.5 \%)$ are highest followed by $41-50$ years $(14.6 \%)$ are lowest.

\begin{tabular}{|c|c|c|c|c|}
\hline Age & Frequency & Percent & Valid Percent & Cumulative Percent \\
\hline 18-30 Years & 30 & 62.5 & 62.5 & 62.5 \\
\hline 31-40 Years & 11 & 22.9 & 22.9 & 85.4 \\
\hline 41-50 Years & 7 & 14.6 & 14.6 & 100 \\
\hline Total & 48 & 100 & 100 & \\
\hline
\end{tabular}

Table 3. Frequency of periapical lesion management amongst gender. Out of which male are highest (54.2\%).

\begin{tabular}{|c|c|c|c|c|}
\hline Gender & Frequency & Percent & Valid Percent & Cumulative Percent \\
\hline Female & 22 & 45.8 & 45.8 & 45.8 \\
\hline Male & 26 & 54.2 & 54.2 & 100 \\
\hline Total & 48 & 100 & 100 & \\
\hline
\end{tabular}

Table 4. Frequency of teeth underwent periapical lesion management. Out of which anterior teeth are highest (89.6\%).

\begin{tabular}{|c|c|c|c|c|}
\hline Teeth & Frequency & Percent & Valid Percent & Cumulative Percent \\
\hline Anterior & 43 & 89.6 & 89.6 & 89.6 \\
\hline Posterior & 5 & 10.4 & 10.4 & 100 \\
\hline Total & 48 & 100 & 100 & \\
\hline
\end{tabular}


Table 5. Frequency of teeth underwent periapical lesion management. Out of which anterior teeth are highest (89.6\%).

\begin{tabular}{|c|c|c|c|c|}
\hline Periapical Surgery & Frequency & Percent & Valid Percent & Cumulative Percent \\
\hline Not Required & 28 & 58.3 & 58.3 & 58.3 \\
\hline Required & 20 & 41.7 & 41.7 & 100 \\
\hline Total & 48 & 100 & 100 & \\
\hline
\end{tabular}

Graph 1. Bar chart showing the association between teeth and management of periapical lesion, $\mathrm{X}$ axis represents the type of teeth and $\mathrm{Y}$ axis represents number of patients; The association between surgery not required (blue) and surgery required (green) among the different variables was found to be statistically insignificant with a Chi square value of 0.772 and $\mathrm{p}$ value of $0.380(\mathrm{p}>0.05)$.

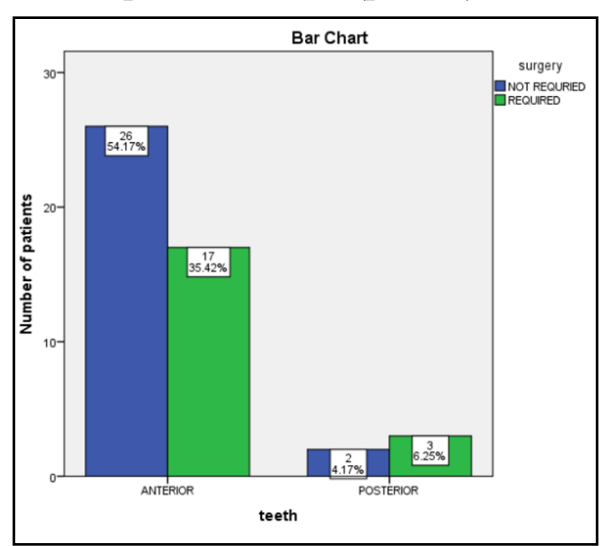

Graph 2. Bar chart representing age group that did not require surgical management and required surgical management. $\mathrm{X}$ axis represents the age of the patient and $\mathrm{Y}$ axis represents the number of patients; the association between surgery not required (blue) and surgery required (green) among the different variables was found to be statistically insignificant with a Chi square value of 2.533 and $p$ value of $0.282(p>0.05)$.

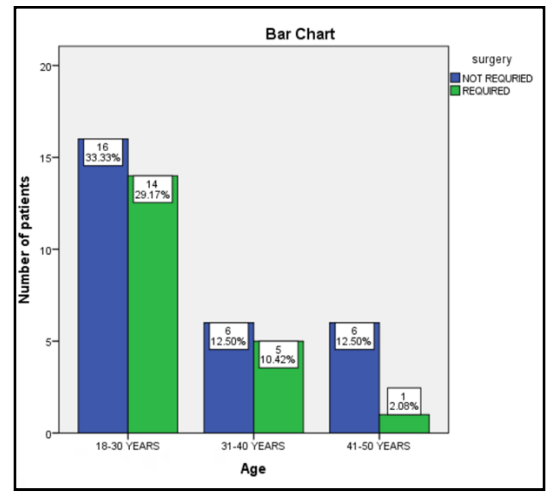

Graph 3. Bar chart representing gender group that did not require surgical management and teeth that required surgical management, $\mathrm{X}$ Axis- Representing gender of the patients and Y Axis- Representing number of patients; the association between surgery not required (blue) and surgery required (green) among the different variables was found to be statistically insignificant with a Chi square value of 0.240 and $p$ value of $0.770(p>0.05)$.

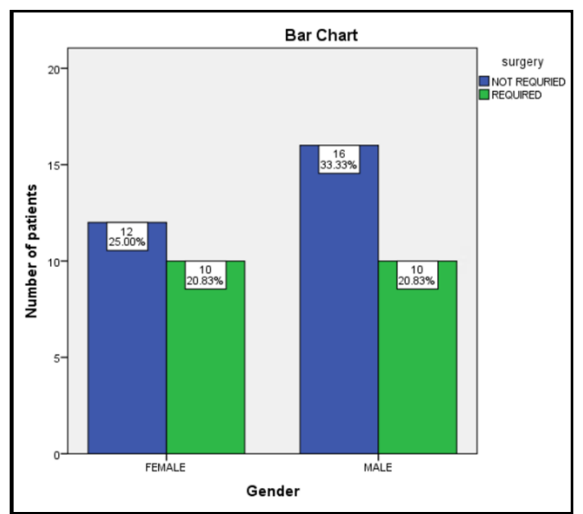


Graph 4. Bar Chart Showing Association Between Lesion Sizes and Number of Visits for non surgical management of lesion, $\mathrm{X}$ Axis representing size of the lesion and Y Axis representing number of patients; blue colour depicts one visit for lesion management, orange color depicts two visit for lesion management. In lesion size greater than $3 \mathrm{X} 3 \mathrm{~mm} 10.71 \%$ are managed in one visit and in lesion size greater than $3 \mathrm{X} 3 \mathrm{~mm} 78.57 \%$ are managed in two visits, $10.71 \%$ are managed in one visit.

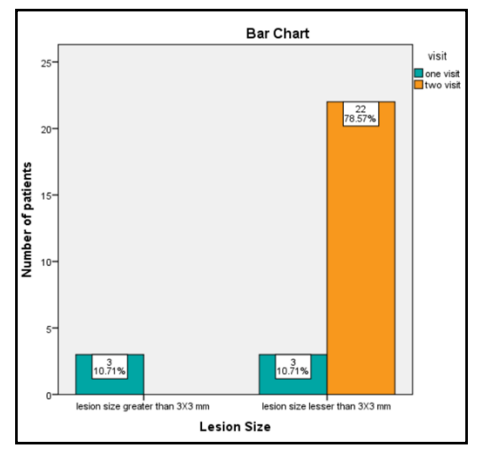

Graph 5. Bar chart showing association between lesion sizes and type of medicament used in non surgical management. $X$ Axis representing size of the lesion and Y Axis representing number of patients; red color depicts calcium hydroxide and green color depicts triple antibiotic paste. In lesion size greater than $3 \mathrm{X} 3 \mathrm{~mm} \mathrm{10.71 \%} \mathrm{are} \mathrm{managed} \mathrm{with} \mathrm{triple} \mathrm{antibiotic}$ paste and in lesion size greater than $3 \times 3 \mathrm{~mm} 75.00 \%$ are managed with calcium hydroxide, $10.71 \%$ are managed with triple antibiotic paste.

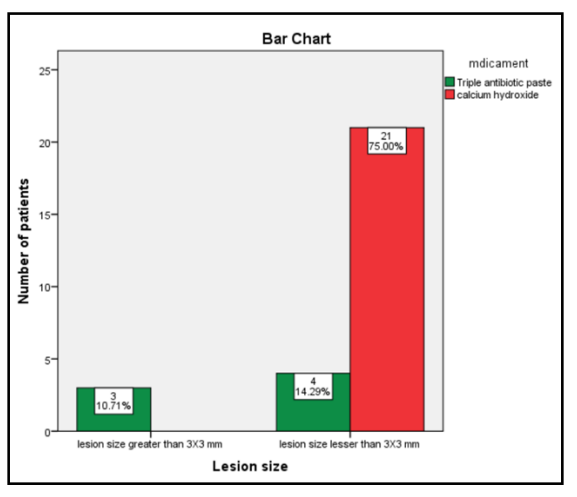

and lesion management is shown in (graph 2) and the association between gender and lesion management is shown in (graph 3). Association between lesion size and number of visits is shown in (graph 4), lesion size greater than $3 \times 3 \mathrm{~mm}$ are 3 and lesion size lesser than $3 \times 3 \mathrm{~mm}$ are 25 . The association between lesion size and type of medicament used is shown in (graph 5).

Fish in 1939, entrenched that the root canal was the bench of infection [50]. The harmful items discharged by disturbance and obliteration of the periapical tissues, because of which the periapical lesion was established [51]. Therefore, it can be presumed that if the root canal system is debrided thoroughly of all the necrotic material, release of toxic products to the tooth apical area will refrain and conditions favorable for repair of the periapical lesion will be established [52]. Certain administrations may fasten regression of pathosis and initiation of the reparative process. One such technique was described by Bhaskar 1972, who suggested that whenever a periapical lesion is evident on a radiograph, instrumentation should be carried $1 \mathrm{~mm}$ ahead of the apical foramen [36]. This may cause sub epithelial hemorrhage with ulceration of the epithelial lining, resulting in resolution of the cyst.

Bender et al., 1972 stated that penetration of the periapical area to the centre of the lesion may help in resolution by establishing the drainage and allay the pressure [53]. Once the exuberance fluid is drained, fibroblasts start to proliferate and deposit collagen, this comprises the capillary network and epithelial cells are thus starved, undergo degeneration and are engulfed by macrophages
[54].

Non surgical management of the periapical lesion reported in this study is $58.3 \%$ in the period of one year. Prospective study done by Shah et al., 1988 showed $84.35 \%$ of cases were treated non surgically [1]. In a retrospective study, Bence and coworkers reported a success rate of $82.2 \%$ with conservative endodontic management of 5000 teeth by three operators [55]. In another study Barbakow and associates reported a success rate of $89 \%$, but their follow-up period was only one year [56]. Anterior teeth are more most affected because of the traumatic injuries. In this study $89.6 \%$ of anterior teeth are managed endodontically for periapical lesions. Male patients are more (54.2\%) because of the traumatic injuries, road traffic accidents are seen more in these patients which lead to damage to the teeth. Age groups of 18-30 years are treated non surgically because of the faster healing capacity of the young age group.

Until the 1960s, endodontists, pathologists and oral and maxillofacial surgeons considered that apical cysts would not react to root canal treatment alone and that periapical surgery was always necessary [57]. However, this concept has changed. Histopathological considers have demonstrated a comparative pervasiveness of granulomas and apical cysts $[16,58,59]$. Healing of apical periodontitis in $80-95 \%$ cases after root canal treatment alone suggest that cysts may heal without periapical surgery [60]. By contrast, a few studies based on meticulous serial sectioning of lesions retrieved in total have shown that the actual incidence of radicu- 
lar cysts in approximately 15\% of all periapical lesions. In background, Simon (1980) and Nair (1998) revealed that 'there are fale cysts and true cysts'. The true cyst is an inflammatory apical lesion with the cavity totally recuperated by stratified squamous epithelium, containing fluid or semisolid tissue in its lumen and without an opening or connection with apical foramen or root canal. The apical true cyst is less likely to be resolved without surgical interference $[61,62]$. On the other hand, those containing epithelial lined cavities or periapical pocket cyst may heal completely after endodontic treatment. The pervasiveness of true cyst is apparently around $9.0 \%$ explaining some apical refractory lesions [60].

The success of non surgical treatment was based on proper cleaning, shaping, disinfection and filling of the root canal system [63-66]. A calcium hydroxide paste dressing is useful as it removes remaining microorganisms from the root canal system [67-70], and may promote periapical healing by 1) controlling the inflammatory reaction by hygroscopic action, calcium proteinate bridge formation and phospholipase inhibition. 2) Neutralizing osteoclastic activity. 3) inducing cellular differentiation. 4) inducing mineralization and 5) neutralization of endotoxins [71-73]. As intracanal medicament, calcium hydroxide is progressively removed through its solubility in circulating periapical fluid, periodic renewal of calcium hydroxide is therefore of fundamental importance. In physical, chemical and biological context, the related events included in the recovery of this extensive periapical lesion might be a) effect of biomechanical preparation, b) lesion decompression established by apical patency by mechanical opening of root foramen, c) disinfectant action of calcium hydroxide because of alkalinity, d) action of calcium hydroxide on bony repair and e) action of immune system on epithelial component of the lesion [71-73].

From the present study, the following observations are made:

1. Conservative endodontic management is desirable in all cases, irrespective of age and gender. Therefore, an attempt must be made to treat patients conservatively as far as possible.

2. Anterior and posterior teeth can be treated non surgically.

3. Young patients that are between the age group of 18 to 30 years did not require surgery, non surgical management was more prefered in these patients.

\section{Conclusion}

Within the limitations of the study, nonsurgical management of the teeth can be done.This will simplify the treatment and conserve the tooth and adjacent structures. A total of 48 teeth exhibiting signs and symptoms or radiographic evidence of periapical disease were treated endodontically, irrespective of the age and sex of the patients. $58.3 \%$ of the teeth were treated non surgically and $41.7 \%$ of the teeth were treated surgically. The use of proper irrigants and medicaments helped in management of teeth, conserving the bone and adjacent structures.

\section{Clinical Significance}

Our present study results revealed that, most of the large periapical lesions $(>3 * 3 \mathrm{~mm})$ were managed successfully using non surgical root canal treatment. So, this would give a significant contribution to future studies. Age would be the clinical significant factor responsible for healing and success rates. Introduction of current trends of disinfection and technology the clinical success of non surgical root canal treatment is improved drastically. Hence, future studies can concentrate on the above mentioned factors in depth to analyse their significant contribution to primary success of non surgical root canal treatment.

\section{Acknowledgement}

With Sincere gratitude, we acknowledge the staff members of the department of Conservative Dentistry and Endodontics, Saveetha Dental College and study participants for their extended support towards the completion of research.

\section{References}

[1]. Shah N. Nonsurgical management of periapical lesions: a prospective study. Oral Surg Oral Med Oral Pathol. 1988 Sep;66(3):365-71.Pubmed PMID: 3174072 .

[2]. Nivethithan T, Raj JD. Endodontic pain-cause and management: A review. Int JPharm. Sci. 2015 Jul 1;6(7):2723.

[3]. Ramesh S. Pain management in endodontics. J. Pain Manag. 2013 Oct $1 ; 6(4): 281$.

[4]. Samuel DS, Duraisamy R, Kumar MP. Cone-beam computed tomography and its applications in dentistry. Drug Invention Today. 2019 Jan 15;12(1).

[5]. Nivesh Krishna R, Pradeep S. Recent diagnostic aids in endodontics-a review. Int J Pharm Clin Res. 2016;8(8):1159-62.

[6]. Ramamoorthi S, Nivedhitha MS, Divyanand MJ. Comparative evaluation of postoperative pain after using endodontic needle and EndoActivator during root canal irrigation: A randomised controlled trial. Aust Endod J. 2015 Aug;41(2):78-87.Pubmed PMID: 25195661.

[7]. Ramanathan S, Solete P. Cone-beam Computed Tomography Evaluation of Root Canal Preparation using Various Rotary Instruments: An in vitro Study. J Contemp Dent Pract. 2015 Nov 1;16(11):869-72.

[8]. Siddique R, Sureshbabu NM, Somasundaram J, Jacob B, Selvam D. Qualitative and quantitative analysis of precipitate formation following interaction of chlorhexidine with sodium hypochlorite, neem, and tulsi. J Conserv Dent. 2019 Jan-Feb;22(1):40-47.Pubmed PMID: 30820081.

[9]. Rajakeerthi R, Ms N. Natural Product as the Storage medium for an avulsed tooth-A Systematic Review. Cumhur Dent J. 2019;22(2):249-56.

[10]. Salamat K, Rezai RF. Nonsurgical treatment of extraoral lesions caused by necrotic nonvital tooth. Oral Surg Oral Med Oral Pathol. 1986 Jun;61(6):61823.Pubmed PMID: 3459992.

[11]. Rajendran R, Kunjusankaran RN, Sandhya R, Anilkumar A, Santhosh R, Patil SR. Comparative Evaluation of Remineralizing Potential of a Paste Containing Bioactive Glass and a Topical Cream Containing Casein Phosphopeptide-Amorphous Calcium Phosphate: An in Vitro Study. Pesqui. Bras. Odontopediatria Clin. Integr. 2019;19:1-10.

[12]. Hussainy SN, Nasim I, Thomas T, Ranjan M. Clinical performance of resinmodified glass ionomer cement, flowable composite, and polyacid-modified resin composite in noncarious cervical lesions: One-year follow-up. J Conserv Dent. 2018 Sep-Oct;21(5):510-515.Pubmed PMID: 30294112.

[13]. Kumar D, Antony S. Calcified Canal and Negotiation-A Review. Res J Pharm Technol. 2018;11(8):3727-30.

[14]. Ravinthar K. Recent advancements in laminates and veneers in dentistry. Res J Pharm Technol. 2018;11(2):785-7.

[15]. Bhaskar SN. Oral surgery--oral pathology conference No. 17, Walter Reed Army Medical Center. Periapical lesions--types, incidence, and clinical features. Oral Surg Oral Med Oral Pathol. 1966 May;21(5):657-71.Pubmed PMID: 5218749.

[16]. Lalonde ER, Luebke RG. The frequency and distribution of periapical cysts and granulomas. An evaluation of 800 specimens. Oral Surg Oral Med Oral Pathol. 1968 Jun;25(6):861-8.Pubmed PMID: 5239741.

[17]. Subramaniam, K., Sethu, G. \& Lochana, P. Radicular cyst. Drug Invention Today.2019; 11.

[18]. Ramachandran Nair PN, Pajarola G, Schroeder HE. Types and incidence of human periapical lesions obtained with extracted teeth. Oral Surg Oral Med Oral Pathol Oral Radiol Endod. 1996 Jan;81(1):93-102.Pubmed PMID: 8850492 .

[19]. Schulz M, von Arx T, Altermatt HJ, Bosshardt D. Histology of periapical lesions obtained during apical surgery. J. Endod. 2009 May 1;35(5):634-42.

[20]. Mobeen, N.Incidence of Common Periapical Lesions-An Intra Oral Periapi- 
cal Radiographic Study. Res J Pharm Biol Chem Sci.2017; 9:1099.

[21]. Natkin E, Oswald RJ, Carnes LI. The relationship of lesion size to diagnosis, incidence, and treatment of periapical cysts and granulomas. Oral Surg Oral Med Oral Pathol. 1984 Jan;57(1):82-94.Pubmed PMID: 6364008.

[22]. Teja KV, Ramesh S, Priya V. Regulation of matrix metalloproteinase-3 gene expression in inflammation: A molecular study. J. Conserv. Dent. 2018 Nov;21(6):592-596.

[23]. Eversole LR. Clinical outline of oral pathology: diagnosis and treatment. PMPH-USA; 2001.

[24]. Rohrer MD. Clinical outline of oral pathology: Diagnosis and treatment, 3rd edition. Edited by Lewis R. Eversole. Lea \& Febiger, Philadelphia, Pennsylvania.1992; Head \& Neck. 14: 522-522.

[25]. Mohanty S, Ramesh S. Interdisciplinary management of large periapical lesion: A case report. J. Adv. Pharm. Educ. Res.2017 Jul-Sep;7(3).

[26]. Malli Sureshbabu N, Selvarasu K, V JK, Nandakumar M, Selvam D. Concentrated Growth Factors as an Ingenious Biomaterial in Regeneration of Bony Defects after Periapical Surgery: A Report of Two Cases. Case Rep Dent. 2019 Jan 22;2019:7046203.Pubmed PMID: 30805222.

[27]. Ranganath, A. \& Nasim, I. Surgical management of a periapical lesion with platelet-rich fibrin-A case report. J. Adv. Pharm. Educ. Res.2017 Jul-Sep:7.

[28]. Baskran RN, Pradeep S. Recent advancement of local anasthesia advancement to recent advancement of local anaesthesia administration. Res J Pharm Technol. 2016;9(10):1761-4

[29]. Hirsch JM, Ahlström U, Henrikson PÅ, Heyden G, Peterson LE. Periapical surgery. Int. J. Oral Surg. 1979 Jun 1;8(3):173-85.

[30]. Rajendran T, Venugopalan S. Role of Polylactic Acid in Bone Regeneration-A Systematic Review. Res. J. Pharm. Biol. Chem. Sci. 2015 Nov 1;7(11):960.

[31]. Moiseiwitsch JR, Trope M. Nonsurgical root canal therapy treatment with apparent indications for root-end surgery. Oral Surg Oral Med Oral Pathol Oral Radiol Endod. 1998 Sep;86(3):335-40.Pubmed PMID: 9768425.

[32]. Al-Kandari AM, Al-Quoud OA, Gnanasekhar JD. Healing of large periapical lesions following nonsurgical endodontic therapy. Quintessence Int. 1994 Feb 1;25(2):115-119.

[33]. Paul, B. \& Dube, K. Healing of Large Periapical Lesions by Non-surgical Approach - Case Reports. Br J Med Med Res.2015; 10: 1-6.

[34]. Rene Jochebed S , Raj JD [No title]. (2016)

[35]. Sommer RF, Ostrander FD, Crowley MC. Clinical endodontics: a manual of scientific endodontics. Saunders; 1966.

[36]. Bhaskar SN. Nonsurgical resolution of radicular cysts. Oral Surg Oral Med Oral Pathol. 1972 Sep;34(3):458-68.Pubmed PMID: 4505760

[37]. Noor S. Chlorhexidine: Its properties and effects. Res J Pharm Technol. 2016;9(10):1755-60

[38]. Janani K, Palanivelu A, Sandhya R. Diagnostic accuracy of dental pulse oximeter with customized sensor holder, thermal test and electric pulp test for the evaluation of pulp vitality: an in vivo study. Braz. Dent. Sci. 2020 Jan $31 ; 23(1): 8$.

[39]. Jose J, Subbaiyan H. Different Treatment Modalities followed by Dental Practitioners for Ellis Class 2 Fracture-A Questionnaire-based Survey. Open Dent. J. 2020 Feb 18;14(1):59-65.

[40]. Nallaswamy D, Subha M. Effects of flipped class based teaching in orthodontics \& dentofacial orthopedics-A prospective study. Int. j. res. 2019 Apr 29;10(2):1415-9.

[41]. Lin LM, Huang GT, Rosenberg PA. Proliferation of epithelial cell rests, formation of apical cysts, and regression of apical cysts after periapical wound healing. J Endod. 2007 Aug;33(8):908-16.Pubmed PMID: 17878074.

[42]. ENDODONTICS.3rd edn By: E. Nicholls. Australian Endodontic Newsletter.2010; (10)13-13

[43]. Alex GP, Rao CV, Marayanan LL. Apical surgery of a rare case of three rooted maxillary second premolar. Endodontology. 2000;12:13-7.

[44]. Neaverth EJ, Burg HA. Decompression of large periapical cystic lesions. J Endod. 1982 Apr;8(4):175-82.Pubmed PMID: 6951918.

[45]. Nandakumar M, Nasim I. Comparative evaluation of grape seed and cranberry extracts in preventing enamel erosion: An optical emission spectrometric analysis. J Conserv Dent. 2018 Sep-Oct;21(5):516-520.Pubmed PMID: 30294113

[46]. Sjögren UL, Hägglund B, Sundqvist G, Wing K. Factors affecting the longterm results of endodontic treatment. J. Endod. 1990 Oct 1;16(10):498504

[47]. Calişkan MK, Sen BH. Endodontic treatment of teeth with apical periodontitis using calcium hydroxide: a long-term study. Endod. Dent. Traumatol.. 1996 Oct 1;12(5):215-21.

[48]. Murphy WK, Kaugars GE, Collett WK, Dodds RN. Healing of periapical radiolucencies after nonsurgical endodontic therapy. Oral Surg Oral Med Oral Pathol. 1991 May 1;71(5):620-4.

[49]. Calişkan MK. Prognosis of large cyst-like periapical lesions following nonsurgical root canal treatment: a clinical review. Int Endod J. 2004 Jun;37(6):408-16.Pubmed PMID: 15186249

[50]. Fish, E. W. \& Wilfred Fish, E. Bone Infection. J Am Dent Assoc.1939; 26: 691-712.

[51]. Hoen MM, LaBounty GL, Strittmatter EJ. Conservative treatment of persistent periradicular lesions using aspiration and irrigation. J Endod. 1990 Apr;16(4):182-6.Pubmed PMID: 2074410.

[52]. Morse DR, Bhambhani SM. A dentist's dilemma: nonsurgical endodontic therapy or periapical surgery for teeth with apparent pulpal pathosis and an associated periapical radiolucent lesion. Oral Surg Oral Med Oral Pathol. 1990 Sep;70(3):333-40.Pubmed PMID: 2216362.

[53]. Bender IB. A commentary on General Bhaskar's hypothesis. Oral Surg Oral Med Oral Pathol. 1972 Sep;34(3):469-76.Pubmed PMID: 4505761.

[54]. Fernandes M, de Ataide I. Nonsurgical management of periapical lesions. J. Conserv. Dent. 2010 Oct;13(4):240-245

[55]. Bence R, Meyers RD, Knoff RV. Evaluation of 5,000 endodontic treatments: incidence of the opened tooth. Oral Surg Oral Med Oral Pathol. 1980;49(1):82-4.Pubmed PMID: 6927945.

[56]. Barbakow FH, Cleaton-Jones PE, Friedman D. Endodontic treatment of teeth with periapical radiolucent areas in a general dental practice. Oral Surg Oral Med Oral Pathol. 1981 May;51(5):552-9.Pubmed PMID: 6941147.

[57]. Winstock D. Apical disease: an analysis of diagnosis and management with special reference to root lesion resection and pathology. Ann R Coll Surg Engl. 1980 May;62(3):171-9.Pubmed PMID: 7396345.

[58]. Spatafore CM, Griffin JA Jr, Keyes GG, Wearden S, Skidmore AE. Periapical biopsy report: an analysis of over a 10-year period. J Endod. 1990 May;16(5):239-41.doi:10.1016/s0099-2399(06)81679-1.PMID: 2074420.

[59]. Love RM, Firth N. Histopathological profile of surgically removed persistent periapical radiolucent lesions of endodontic origin. Int Endod J. 2009 Mar;42(3):198-202.Pubmed PMID: 19228208

[60]. Soares J, Santos S, Silveira F, Nunes E. Nonsurgical treatment of extensive cyst-like periapical lesion of endodontic origin. Int Endod J. 2006 Jul;39(7):566-75.Pubmed PMID: 16776761.

[61]. New Perspectives On Radicular Cysts: Do They Heal? Australian Endodontic Journal.1998; 24:127-127.

[62]. Simon JH. Incidence of periapical cysts in relation to the root canal. J Endod. 1980 Nov;6(11):845-8.Pubmed PMID: 6935342.

[63]. Ragul P, Dhanraj M, Jain AR. Irrigation technique used in cleaning and shaping during endodontic treatment-A review. Drug Invention Today. 2018 May 1;10(5)

[64]. Jain P, Ranjan M. Role of herbs in root canal irrigation-A review. IOSR j. pharm. biol. sci. 2014;9(2):06-10.

[65]. Sriraman P, Neelakantan P. Asepsis in operative dentistry and endodontics. Int. J. Public Health. 2014 Mar;3(1):1-6.

[66]. Teja KV, Ramesh S. Shape optimal and clean more. Saudi Endod. J. 2019 Sep 1;9(3):235.

[67]. Siqueira JF Jr, Lopes HP. Mechanisms of antimicrobial activity of calcium hydroxide: a critical review. Int Endod J. 1999 Sep;32(5):361-9.Pubmed PMID: 10551109.

[68]. Weiger R, Rosendahl R, Löst C. Influence of calcium hydroxide intracanal dressings on the prognosis of teeth with endodontically induced periapical lesions. Int Endod J. 2000 May;33(3):219-26.Pubmed PMID: 11307438.

69]. Manohar MP, Sharma S. A survey of the knowledge, attitude, and awareness about the principal choice of intracanal medicaments among the general dental practitioners and nonendodontic specialists. Indian J Dent Res. 2018 Nov-Dec;29(6):716-720.Pubmed PMID: 30588997.

[70]. Raj JD , Ramesh S, Khirtika SG. Management of horizontal root fractures at various levels: A case series. Journal of Advanced Pharmacy Education \& Research. 2018; Jul-Sep7.

[71]. 71. Hosoya N, Takahashi G, Arai T, Nakamura J. Calcium concentration and $\mathrm{pH}$ of the periapical environment after applying calcium hydroxide into root canals in vitro. J Endod. 2001 May;27(5):343-6.Pubmed PMID: 11485253.

[72]. Kim M, Kim B, Yoon S. Effect on the healing of periapical perforations in dogs of the addition of growth factors to calcium hydroxide. J Endod. 2001 Dec;27(12):734-7.Pubmed PMID: 11771578.

[73]. VERNIEKS AA, MESSER LB. Calcium hydroxide induced healing of periapical lesions: a study of 78 non-vital teeth. Int. Endod J. 1978 Jul;11(2):61- 